\title{
Experimental on Flexural Strength of Glass/Kevlar and Glass/Carbon Hybrid Composite Laminates
}

\author{
Ramya Suresh, K.Senthilnathan, S.Prasannaraj Yadav, S.Karthick
}

\begin{abstract}
-our present study deals with the investigation of flexural strength of Glass/Kevlar epoxy and glass/carbon epoxy hybrid laminates. Laminates of different stacking order were prepared and three point bending test were conducted on the hybrid laminates. From the experimental results, the flexural strength of different hybrid laminates was evaluated and comparisons were made.
\end{abstract}

Keywords- hybrid, three point bending, glass/carbon, glass/Kevlar.

\section{INTRODUCTION}

Hybrid composites combine two or more different kinds of fibres. They are found out to be more versatile and favourable as the advantage of one type of fiber supplements for the disadvantages of other fibres. Proper material design of hybrid composites can lead to low cost and high performance components. Due to the better material properties of hybrid composites such as strength to density and stiffness to density ratios as compared with most metals they are used in automobile, aerospace, infrastructure and marine applications. The measurement of behaviour of materials subjected to simple beam loading is known as Flexure test method. Flexural strength is defined as the maximum stress in the outermost fiber.

There have been many research studies which focus on finding the flexural strength and flexure modulus of various hybrid composite laminates. Chensong Dong et al [1] studied the flexural strength properties of hybrid composites made of S2glass and T700S carbon. The specimens were manufactured using hand layup process and tested according to ASTM D790-07 standards with span to depth ratio taken as 32. They observed that the dominant mode of failure was the compressive failure. They also concluded that positive hybrid effects exist by substituting carbon fibers with glass fibers. Jin Zhang et al[2] investigated five types of laminates with different stacking sequence of glass and carbon fibers under tensile, compressive and flexural bending subjected to

Revised Manuscript Received on 14 September, 2019.

Mrs.Ramya Suresh, Assistant Professor, Department of Mechanical Engineering, Easwari Engineering College, Chennai,Tamil Nadu, India. (Email: ramyashg@gmail.com)

Mr.K.Senthilnathan, Assistant Professor, Department of Mechanical Engineering, Easwari Engineering College, Chennai(Tamil Nadu), India. (Email: senthil.016@gmail.com)

Dr. S.Prasannaraj Yadav, Associate Professor, Department of Mechanical Engineering, Easwari Engineering College, Chennai,Tamil Nadu, India. (Email: sprasannarajyadav@ gmail.com)

Mr.S,Karthick Assistant Professor, Department of Mechanical Engineering, Easwari Engineering College, Chennai,Tamil Nadu, India.(Email: mitkarthick@gmail.com) static loading. They observed that the hybrid laminate with carbon layers at the exterior provided the best flexural properties while the alternating glass/carbon ply provided the highest compressive strength and also the tensile strength is independent or irrelevant to the stacking sequence

E. Sideridis and G.A. Papadopoulos [3] analysed the flexural properties of unidirectional glass fiber reinforced epoxy resin specimen in the $0^{\circ}, 15^{\circ}, 30^{\circ}, 45^{\circ}, 60^{\circ}, 75^{\circ}$ and $90^{\circ}$ fiber directions with high span to thickness ratios. The flexure modulus of the laminates was evaluated with varying $\mathrm{L} / \mathrm{t}$ ratios. F. Mujika[4] studied the three point bending test under the influence of shear and local deformation effects in the load application and supports. The test was carried out on specimens of carbon/ epoxy unidirectional composite with different stacking order. He observed that the local deformation effects played an important role over the effects of shear in small span length and also large thickness.

The aim of our paper is to study the flexural strength of carbon/glass and Kevlar/glass epoxy hybrid composites experimentally and compare their flexural strength for different stacking order. This study also aims at seeing Kevlar fiber as a suitable substitute for carbon fibers used in various marine and aerospace applications.

\section{EXPERIMENTAL PROCEDURE}

\section{A. Specimen Preparation}

The laminates were prepared using hand layup method. The fibers used for this study acquired were unidirectional glass, carbon fibers and commercially available bidirectional Kevlar mats. The resin used is epoxy LY 556 and the hardener HY951. The ratio of resin to fibers is 60 to 40 by weight and the hardener weight is 10 percent of resin weight. Partial curing is done in atmospheric condition for 3 hours. Post curing is done at a pressure of 70 bar at $70^{\circ} \mathrm{C}$ for 10 minutes in the compression moulding machine. The flexure test specimens were prepared according to ASTM D790-07 standards. The ratio of support span to depth ratio used is 32:1 with support span of $13 \mathrm{~mm}$ on either side and the width of the specimens were taken as $15 \mathrm{~mm}$. The laminates prepared for the experimental study is tabulated and their abbreviations used in TableI. 
Table I : Hybrid Laminates Prepared

\begin{tabular}{|l|l|}
\hline $\begin{array}{l}\text { HYBRID LAMINATES } \\
\text { PREPARED }\end{array}$ & ABBREVIATION \\
\hline$\left[\mathrm{K}_{\mathrm{B}} / \mathrm{K}_{\mathrm{B}} / \mathrm{G}_{0} / \mathrm{G}_{-45} / \mathrm{G} 90 / \mathrm{G}_{45}\right]_{\mathrm{S}}$ & KK-G \\
\hline$\left[\mathrm{K}_{\mathrm{B}} / \mathrm{G}_{0} / \mathrm{G}_{0} / \mathrm{G}_{-45} / \mathrm{G}_{90} / \mathrm{G}_{45}\right]_{\mathrm{S}}$ & $\mathrm{K}-\mathrm{G}$ \\
\hline$\left[\mathrm{C}_{0} / \mathrm{C}_{0} / \mathrm{G}_{0} / \mathrm{G}_{-45} / \mathrm{G} 0 / \mathrm{G}_{45}\right]_{\mathrm{S}}$ & $\mathrm{CC}-\mathrm{G}$ \\
\hline$\left[\mathrm{C}_{0} / \mathrm{G}_{0} / \mathrm{G}_{0} / \mathrm{G}_{-45} / \mathrm{G}_{90} / \mathrm{G}_{45}\right]_{\mathrm{S}}$ & $\mathrm{C}-\mathrm{G}$ \\
\hline
\end{tabular}

b. Flexure Test

Flexure test was carried out in the UTM as per the ASTM D790-07 standards [5]. The test method utilises a three point bending test. The specimen is simply supported on rollers. The loading nose and supports rollers have a radii are $5 \mathrm{~mm}$. The rate of speed of of crosshead motion was kept as $8 \mathrm{~mm} / \mathrm{min}$ as per the standards. The load - deflection data were generated automatically. The experiment was conducted till the specimen fails.

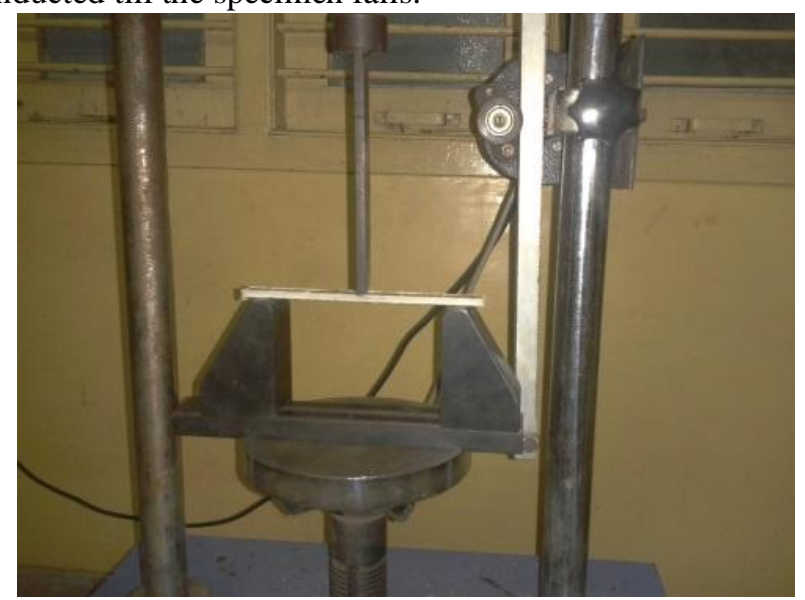

(a)

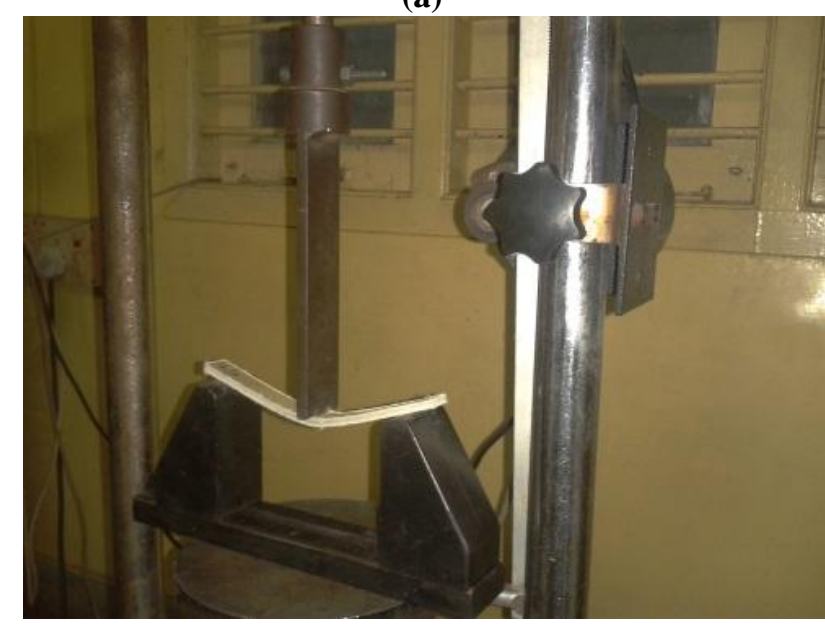

(b)

Fig. 1. Experimental setup for flexure test (a) before testing (b) during testing

\section{RESULTS AND DISCUSSIONS}

From the experimental study, the displacement-load data were recorded and plotted. The damage was visually inspected. The carbon/glass epoxy hybrid laminates damage was observed in both the fibers and matrix with delamination. The Kevlar/glass epoxy hybrid laminates failure was observed in the matrix with layer separation at the glass-Kevlar junction. It was seen that the load versus deflection followed a linear trend until the breaking load and the curve follows a constant line trend with decreasing load. From the load and displacement data obtained, the stress and strain values were calculated. The formula used for evaluating the stress is given by,

$\sigma_{f}=\left(\frac{3 P L}{2 b d^{2}}\right)\left[1+6(\mathrm{D} / \mathrm{L})^{2}-4(\mathrm{~d} / \mathrm{L})(\mathrm{D} / \mathrm{L})\right]$

The strain is calculated using the formula,

$\epsilon_{f}=6 D d / L^{2}$

The flexure modulus is evaluated by using the formula, $E_{B}=L^{3} \mathrm{~m} / 4 \mathrm{bd}$

\section{Where:}

$\sigma_{f}=$ Stress in the outer fibers at midpoint, $\mathrm{MPa}$

$\epsilon_{f}=$ Strain in the outer surface, $\mathrm{mm} / \mathrm{mm}$

$\mathrm{E}_{\mathrm{B}}=$ modulus of elasticity in bending, $\mathrm{MPa}$

$\mathrm{P}=$ Load at a given point on the load-deflection curve, $\mathrm{N}$

$\mathrm{L}=$ support span, $\mathrm{mm}$

$\mathrm{b}=$ width of the beam tested, $\mathrm{mm}$

$\mathrm{d}=$ depth of beam tested, $\mathrm{mm}$

$\mathrm{D}=$ deflection of the centreline of the specimen at the middle of the support span, $\mathrm{mm}$

$\mathrm{m}=$ slope of the tangent to the initial straight-line portion of the load-deflection curve, $\mathrm{N} / \mathrm{mm}$

The load - displacement curve were plotted are shown in Figure 2.

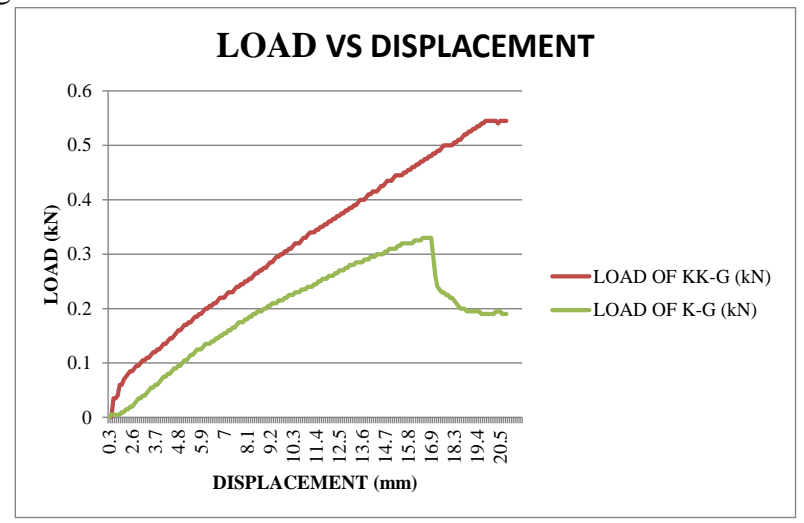

(a)

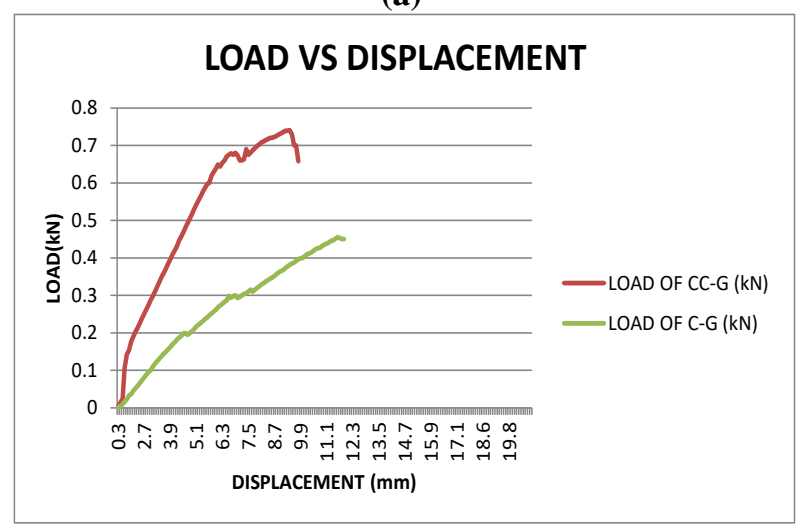

(b)

Fig. 2. Loads versus. Displacement graph (a) Glass/Kevlar epoxy (b) Glass/Carbon epoxy hybrid laminates

From the load - displacement graph the maximum load, displacement at maximum load and the flexure modulus calculated using (3) are listed in Table II.

Published By: 
Table II Flexural Properties

\begin{tabular}{|l|l|l|lr|}
\hline $\begin{array}{l}\text { Specim } \\
\text { en } \\
\text { Layup } \\
\text { Schem } \\
\text { e }\end{array}$ & $\begin{array}{l}\text { Maximu } \\
\mathbf{m} \text { Load } \\
(\mathbf{k N})\end{array}$ & $\begin{array}{l}\text { Displaceme } \\
\text { nt at } \\
\text { Maximum } \\
\text { Load } \\
(\mathbf{m m})\end{array}$ & $\begin{array}{l}\text { Modulus } \\
\text { Elasticity } \\
\text { Bending, } \\
\text { (GPa) }\end{array}$ & $\begin{array}{r}\text { of } \\
\text { EB }\end{array}$ \\
\hline K-G & 0.4 & 17.9 & 16.3 \\
\hline C-G & 0.45 & 7.9 & 30.9 \\
\hline KK-G & 0.55 & 20.9 & 18.2 \\
\hline CC-G & 0.74 & 9.4 & 70.9 \\
\hline
\end{tabular}

From the load- displacement data obtained the corresponding stress-strain data were evaluated using equation (1) and equation (2) and the graph was plotted (Figure 3).

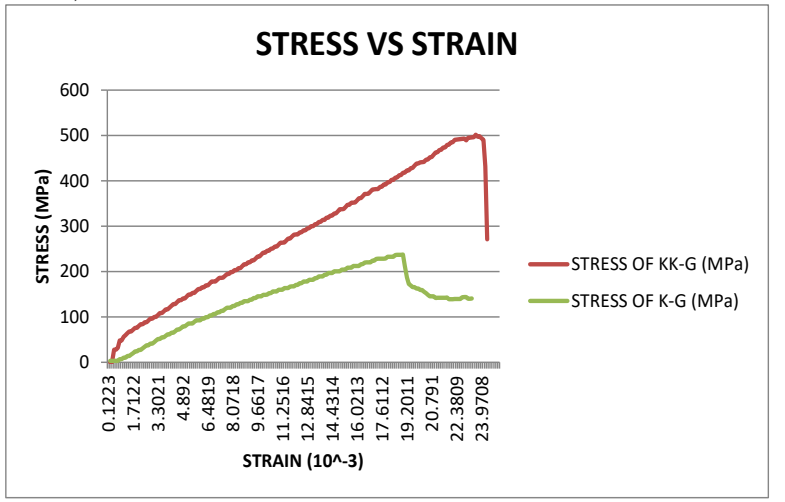

(a)

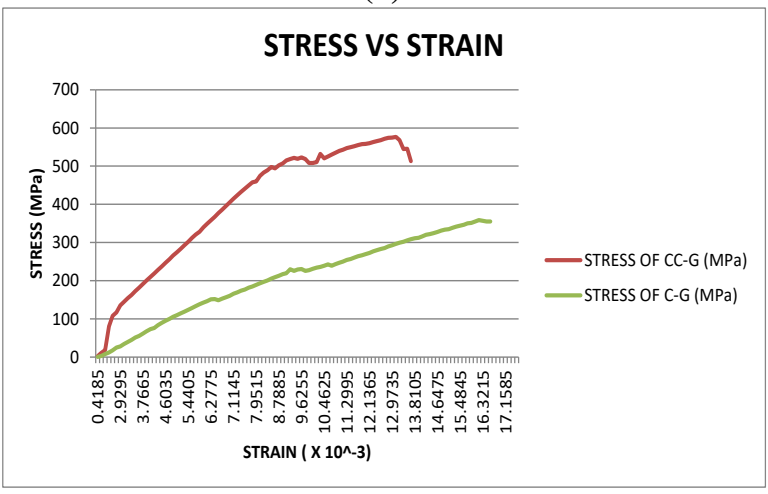

(b)

Fig. 3. Stress versus strain graph (a) glass/Kevlar epoxy (b) glass/carbon epoxy hybrid laminates

Flexural strength is nothing but the maximum stress in the outermost fiber observed at the surface of the specimen on the convex side or tension side. The flexure strength of the each hybrid laminates evaluated is listed in Table 3.

Table II flexural strength of the laminates

\begin{tabular}{|l|l|}
\hline Specimen lay up & Flexural Strength (MPa) \\
\hline K-G & 270 \\
\hline C-G & 358 \\
\hline KK-G & 460 \\
\hline CC-G & 570 \\
\hline
\end{tabular}

From the load- displacement graph it was observed that the glass/Kevlar epoxy and glass/carbon epoxy hybrid laminates exhibited yielding behavior.

\section{CONCLUSIONS}

An experimental study has been carried out to investigate the flexural strength of the hybrid glass/Kevlar epoxy and glass/carbon epoxy composite laminates. Two different stacking orders of the hybrid laminates were investigated. From the above results and discussions, the following conclusions could be summarized as following:

- In case of glass/carbon epoxy hybrid composites failure was characterised with delaminating of layers while the glass/Kevlar epoxy hybrid composites failure was characterised with layer separation at the Kevlar - glass junction.

- The maximum load, displacement at maximum load, flexure modulus and the flexure strength of the hybrid glass/Kevlar epoxy and glass/carbon epoxy composite laminates for two different stacking orders were evaluated.

- It is seen that the glass/Kevlar epoxy hybrid composites, the specimen $\left[\mathrm{K}_{\mathrm{B}} / \mathrm{K}_{\mathrm{B}} / \mathrm{G} 0 / \mathrm{G}_{-45} / \mathrm{G} 90 / \mathrm{G}_{45}\right] \mathrm{s}$ flexure strength was found to be $70 \%$ more than the specimen $\left[\mathrm{K}_{\mathrm{B}} / \mathrm{G}_{0} / \mathrm{G}_{0} / \mathrm{G}_{-45} / \mathrm{G}_{90} / \mathrm{G}_{45}\right]_{\mathrm{s}}$.

- In case of the glass/carbon epoxy hybrid composites, the specimen $\left[\mathrm{C}_{0} / \mathrm{C}_{0} / \mathrm{G} 0 / \mathrm{G}_{-45} / \mathrm{G} 90 / \mathrm{G}_{45}\right]_{\mathrm{s}}$ flexure strength was found to be $21 \%$ more than the specimen $\left[\mathrm{C}_{0} / \mathrm{G}_{0} / \mathrm{G}_{0} / \mathrm{G}_{-45} / \mathrm{G}_{90} / \mathrm{G}_{45}\right]_{\mathrm{s} \text {. }}$

- It is also observed that the percentage variation of the flexural strength between the two hybrid composites ranged from 2 to 37 percentages. The replacement of Kevlar fiber in specimen $\left[\mathrm{K}_{\mathrm{B}} / \mathrm{G}_{0} / \mathrm{G}_{0} / \mathrm{G}_{-45} / \mathrm{G}_{90} / \mathrm{G}_{45}\right]_{\mathrm{s}}$ with carbon fiber at the outermost layer increased the flexure strength by $30 \%$ while the replacement of both the kevlar fiber in specimen $\left[\mathrm{K}_{\mathrm{B}} / \mathrm{K}_{\mathrm{B}} / \mathrm{G} 0 / \mathrm{G}_{-45} / \mathrm{G} 90 / \mathrm{G}_{45}\right]_{\mathrm{S}}$ observed to be almost same with $24 \%$ deviation.

- It can be noted that Kevlar could be a good substitute for carbon fibers if two layers of carbon fibers as the outermost fibers with less weight leading to high strength - density ratio and high stiffness- density ratio.

\section{ACKNOWLEDGMENT}

I wish to express my sincere thanks to Dr.R.S.Kumar, Principal, Dr.V.Elango, Vice-Principal, and Dr. M. Vetrivel Sezhian, Professor and Head, Mechanical Engineering, Easwari Engineering College, Chennai for their valuable guidance, support and encouragement. I also like to thank Dr. V.Antony Aroul Raj, Professor and Research coordinator, Easwari Engineering College, Chennai for his valuable guidance and the institution for allowing us to use the Research Laboratory for the Experimentation work.

\section{REFERENCES}

1. Chensong Dong, Heshan A. Ranaweera-Jayawardena, Ian J. Davies, "Flexural properties of hybrid composites reinforced by S-2 glass and T700S carbon fibers",Elsevier, Composites: Part B 43 (2012),pages 573-581.

2. Jin Zhang, Khunlavit Chaisombat, Shuai He, Chun H. Wang, "Hybrid composite laminates reinforced with glass/carbon woven fabrics for lightweight load bearing 
structures", Elsevier, Materials and Design 36 (2012),pages 75-80

3. E. Sideridis, G. A. Papadopoulos, "Short-Beam and Three-Point-Bending Tests for the Study of Shear and Flexural Properties in Unidirectional-Fiber-Reinforced Epoxy Composites", Journal of Applied Polymer Science, Vol. 93, 63-74 (2004).

4. F. Mujika, "On the effect of shear and local deformation in three-point bending tests", Elsevier, Polymer Testing 26 (2007), pages 869-877.

5. Standard test method for flexural properties of unreinforced and reinforced plastics and electrical insulating materials", D 790-07, ASTM International.

\section{AUTHORS PROFILE}

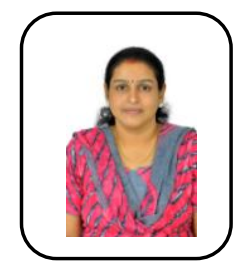

Mrs. Ramya Suresh Assistant Professor, Department of Mechanical Engineering, Easwari Engineering College, Chennai (Tamil Nadu), India. Research interest areas are design,composite materials and vibrations (condition monitoring).Presented papers in international and national conference.Membership in IET,ISTE,SAE.

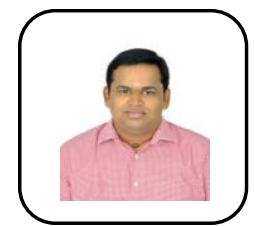

Mr.K.Senthilnathan, Assistant Professor, Department of Mechanical Engineering, Easwari Engineering College, Chennai(Tamil Nadu), India. Research interest areas are IC Engines and thermal engineering.Presented papers in international and national conference. Published papers in various international journals. Membership in IET,ISTE,SAE,ISCA.

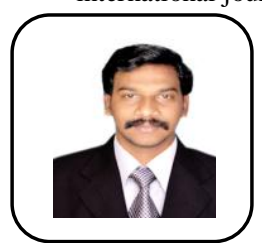

Dr. S.Prasannaraj Yadav, Associate Professor, Department of Mechanical Engineering, Easwari Engineering College, Chennai (Tamil Nadu), India. He has six years of teaching and research experience in handling undergraduate and postgraduate students. He has worked as a senior research fellow in MNRE (Ministry of New Renewable Energy) sponsored project. $\mathrm{He}$ is a life member in ISTE, and annual member in SAE India His research areas include Alternate fuels, IC Engines and Energy Conversion. He has published more than 10 research papers in peer reviewed journals/conferences. He is a reviewer for the Journal Energy - Elsevier Publication

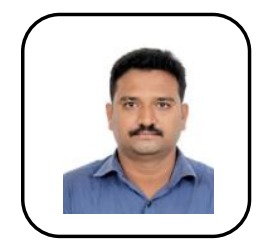

Mr.S,Karthick Assistant Professor, Department of Mechanical Engineering, Easwari Engineering College, Chennai (Tamil Nadu), India..His area of research is Manufacturing Technology and Fluid Mechanics \& Machinery. He has published papers in various international and journals. Membership in IET,ISTE,SAE,ISCA. 